\title{
Performance Evaluation of the Real-Q Cytomegalovirus (CMV) Quantification Kit Using Two Real-Time PCR Systems for Quantifying CMV DNA in Whole Blood
}

\author{
Jong Eun Park, M.D. ${ }^{1}$, Ji-Youn Kim, M.T. ${ }^{2}$, Sun Ae Yun, M.T. ${ }^{2}$, Myoung-Keun Lee, M.T. ${ }^{1}$, Hee Jae Huh, M.D. ${ }^{1}$, \\ Jong-Won Kim, M.D. ${ }^{1}$, and Chang-Seok Ki, M.D. ${ }^{1}$ \\ Department of Laboratory Medicine and Genetics ${ }^{1}$, Samsung Medical Center, Sungkyunkwan University School of Medicine, Seoul; Center for Clinical \\ Medicine $^{2}$, Samsung Biomedical Research Institute, Samsung Medical Center, Seoul, Korea
}

Standardized cytomegalovirus (CMV) DNA quantification is important for managing CMV disease. We evaluated the performance of the Real-Q CMV Quantification Kit (Real-Q assay; BioSewoom, Korea) using whole blood (WB), with nucleic acid extraction using MagNA Pure 96 (Roche Diagnostics, Germany). Real-time PCR was performed on two platforms: the 7500 Fast real-time PCR (7500 Fast; Applied Biosystems, USA) and CFX96 real-time PCR detection (CFX96; Bio-Rad, USA) systems. The WHO international standard, diluted with CMV-negative WB, was used to validate the analytical performance. We used 90 WB clinical samples for comparison with the artus CMV RG PCR kit (artus assay; Qiagen, Germany). Limits of detections (LODs) in 7500 Fast and CFX96 were 367 and $479 \mathrm{IU} / \mathrm{mL}$, respectively. The assay was linear from the LOD to $10^{6} \mathrm{IU} / \mathrm{mL}\left(R^{2} \geq 0.9886\right)$. The conversion factors from copies to IU in 7500 Fast and CFX96 were 0.95 and 1.06 , respectively. Compared with the artus assay, for values $<1,000 \mathrm{copies} / \mathrm{mL}, 100 \%$ of the samples had a variation $<0.7 \log _{10}$ copies $/ \mathrm{mL} ;>1,000$ copies $/ \mathrm{mL}, 73.3 \%$ and $80.6 \%$ of samples in 7500 Fast and CFX96, respectively, had $<0.5 \log _{10}$ copies $/ \mathrm{mL}$. The Real-Q assay is useful for quantifying CMV in WB with the two real-time PCR platforms.

Key Words: Cytomegalovirus, Real-time PCR, Quantification, Whole blood, WHO International Standard, Validation
Received: February 20, 2016

Revision received: April 25, 2016

Accepted: July 1, 2016

Corresponding author: Hee Jae Huh Department of Laboratory Medicine and Genetics, Samsung Medical Center, Sungkyunkwan University School of Medicine, 81 Irwon-ro, Gangnam-gu, Seoul 06351, Korea

Tel: +82-2-3410-1836

Fax: $+82-2-3410-2719$

E-mail: pmhhj77@gmail.com

Co-corresponding author: Chang-Seok Ki Department of Laboratory Medicine and Genetics, Samsung Medical Center, Sungkyunkwan University School of Medicine, 81 Irwon-ro, Gangnam-gu, Seoul 06351, Korea

Tel: +82-2-3410-2709

Fax: +82-2-3410-2719

E-mail: changski@skku.edu

(C) The Korean Society for Laboratory Medicine This is an Open Access article distributed under the terms of the Creative Commons Attribution Non-Commercial License (http://creativecommons.org/licenses/by-nc/4.0) which permits unrestricted non-commercial use, distribution, and reproduction in any medium, provided the original work is properly cited.
Cytomegalovirus (CMV) is a pathogen that causes significant morbidity and mortality in immunocompromised patients, especially organ transplant recipients $[1,2]$. CMV viral load testing is routinely used for diagnosis and decision-making regarding the initiation of preemptive therapy and for monitoring patient response to therapy $[3,4]$. Real-time PCR assays are currently the primary choice for monitoring CMV viral load because of their broad linear range, low limits of detection (LODs) and quantification (LOQs), and small contamination risk [5].

However, viral load tests have shown highly variable results in inter-laboratory comparisons [6]. The first CMV international standard (IS) was developed and approved by the WHO in 2010, making it possible to recalibrate CMV viral load assays according to the standard [7]. Although the use of the IS should improve the consistency of inter-laboratory test results, other test characteristics also affect results, such as the sample type 
used (whole blood [WB] or plasma), the nucleic acid extraction method, and test instrumentation [5].

The Real-Q CMV DNA quantification kit (Real-Q assay; BioSewoom, Seoul, Korea) was developed for quantifying CMV load and was approved by the Korean Ministry of Food and Drug Safety. It targets the CMV glycoprotein B and consists of Taqman reagent, dual hybridization probes, and a primer system. In the present study, we assessed the performance of the Real$Q$ assay for quantifying CMV DNA in WB using two real-time PCR platforms: the 7500 Fast real-time PCR system (7500 Fast; Applied Biosystems, Foster City, CA, USA) and the CFX96 real-time PCR detection system (CFX96; Bio-Rad, Hercules, CA, USA). This study was conducted at a tertiary-care hospital in Seoul, Korea, and it was approved by the Institutional Review Board of Samsung Medical Center.

The WHO IS (NIBSC, code: 09/162, Hertfordshire, Great Britain) was used for evaluating performance [7]. After reconstitution in $1 \mathrm{~mL}$ distilled water, the WHO IS containing $5 \times 10^{6} \mathrm{IU}$ CMV DNA was diluted with CMV-negative WB.

DNA was extracted on a MagNA Pure 96 instrument (Roche Diagnostics, Mannheim, Germany) with the "Pathogen Universal Protocol" (elution volume, $100 \mu \mathrm{L}$ ), according to the procedure recommended by the manufacturer. Detection and quantification of CMV DNA was performed by using the Real-Q assay. The PCR reaction was performed in a total volume of $25 \mu \mathrm{L}$ (15 $\mu \mathrm{L}$ of PCR reaction mixture including probe and primers, plus $10 \mu \mathrm{L}$ of template DNA). The real-time PCR reactions were carried out simultaneously on the 7500 Fast and the CFX96 systems according to the manufacturer's respective instructions. Each PCR run included a set of quantitative calibrators corresponding to 2.0-6.0 $\log _{10}$ copies/mL. The CMV DNA load was calculated from the standard curve and expressed as the number of CMV DNA copies/mL of WB.

The LOD, the point at which 95\% of the replicates of a given viral load are detected, was determined by probit analysis. The LOQ was defined as the lowest level of CMV where the total error was $\leq 1.0 \log _{10} \mathrm{IU} / \mathrm{mL}$ [8]. Serial dilutions of the WHO IS were analyzed with eight replicates per dilution. The linearity of the real-time PCR assay was determined by analyzing a 10-fold dilution series of the WHO IS ranging from the LOD upward to $6.0 \log _{10} \mathrm{IU} / \mathrm{mL}$. Each dilution was tested in triplicate, and the data was subjected to linear regression analysis. To estimate conversion factors, triplicates of WHO IS dilutions with expected values of 5,000 IU/mL were analyzed for five consecutive days. Cross-reactivity was evaluated by using seven viruses: EpsteinBarr virus, herpes simplex virus (HSV)-1, HSV-2, hepatitis B vi-
Table 1. Limits of detection, limits of quantification, and conversion factors for the MagNA Pure 96 system coupled to two distinct amplification platforms

\begin{tabular}{lccc}
\hline Amplification platform & $\begin{array}{c}\text { Limit of } \\
\text { detection } \\
\text { (IU/mL) }\end{array}$ & $\begin{array}{c}\text { Limit of } \\
\text { quantification } \\
\text { (IU/mL) }\end{array}$ & $\begin{array}{c}\text { Conversion } \\
\text { factor } \\
\text { (IU/copies) }\end{array}$ \\
\hline 7500 Fast real-time PCR system & 367 & 367 & 0.95 \\
$\begin{array}{l}\text { CFX96 real-time PCR detection } \\
\text { system }\end{array}$ & 479 & 479 & 1.06 \\
\hline
\end{tabular}

rus, BK virus, respiratory syncytial virus B, and influenza B virus. Nucleic acids isolated from each organism were added to the CMV DNA amplification reactions followed by analysis on both real-time PCR platforms. To validate the clinical performance of the Real-Q assay, a total of 90 clinical WB samples was used, and the results were compared with those of the artus CMV RG PCR kit (artus assay; Qiagen, Hilden, Germany) carried out on a Rotor-Gene $Q$ system (Qiagen).

The LODs were $367 \mathrm{IU} / \mathrm{mL}$ and $479 \mathrm{IU} / \mathrm{mL}$ by the respective real-time PCR platforms (Table 1). The LOQs were identical to the LODs for both real-time PCR platforms. The assay was linear in the range of all samples tested on both PCR platforms (Fig. 1) $\left(R^{2} \geq 0.9886\right)$. Conversion factors were calculated as the IS concentration $(\mathrm{IU} / \mathrm{mL})$ divided by the mean value of a total of 15 results for genomic copies of CMV (copies $/ \mathrm{mL}$ ). The conversion factors were 0.95 and 1.06 for the 7500 Fast and the CFX96, respectively (Table 1 ). In the cross-reactivity tests, no false positive signals were observed on either platform.

A total of 62 nonselective consecutive clinical WB samples were tested by using both the Real-Q and artus assays. The Real-Q and artus assays detected CMV DNA in 10 and nine samples, respectively, with $98.4 \%$ concordance. In addition, 28 archived clinical WB samples were tested by using both assays. To compare the two quantification assays, a total of 37 samples with CMV DNA load above the LOQ in both assays were analyzed with Bland-Altman analysis. The viral load values measured with the Real-Q assay on the 7500 Fast and CFX96 were on average 0.12 and $0.08 \log _{10}$ copies $/ \mathrm{mL}$ lower than those measured with the artus assay, respectively (Fig. 2). Among the samples with CMV DNA load $<3 \log _{10}$ copies $/ \mathrm{mL}$, all samples (100\%) had a variation $<0.7 \log _{10}$ copies $/ \mathrm{mL}$, regardless of the PCR platform used. For values $>3 \log _{10}$ copies $/ \mathrm{mL}$, CMV load values measured with the Real-Q assay on the 7500 Fast and CFX96 showed variation $<0.5 \log _{10}$ copies/mL in 22/30 (73.3\%) and $26 / 31$ (80.6\%) samples, respectively, compared with those analyzed by using the artus assay. Overall, 36/37 (97.3\%) sam- 

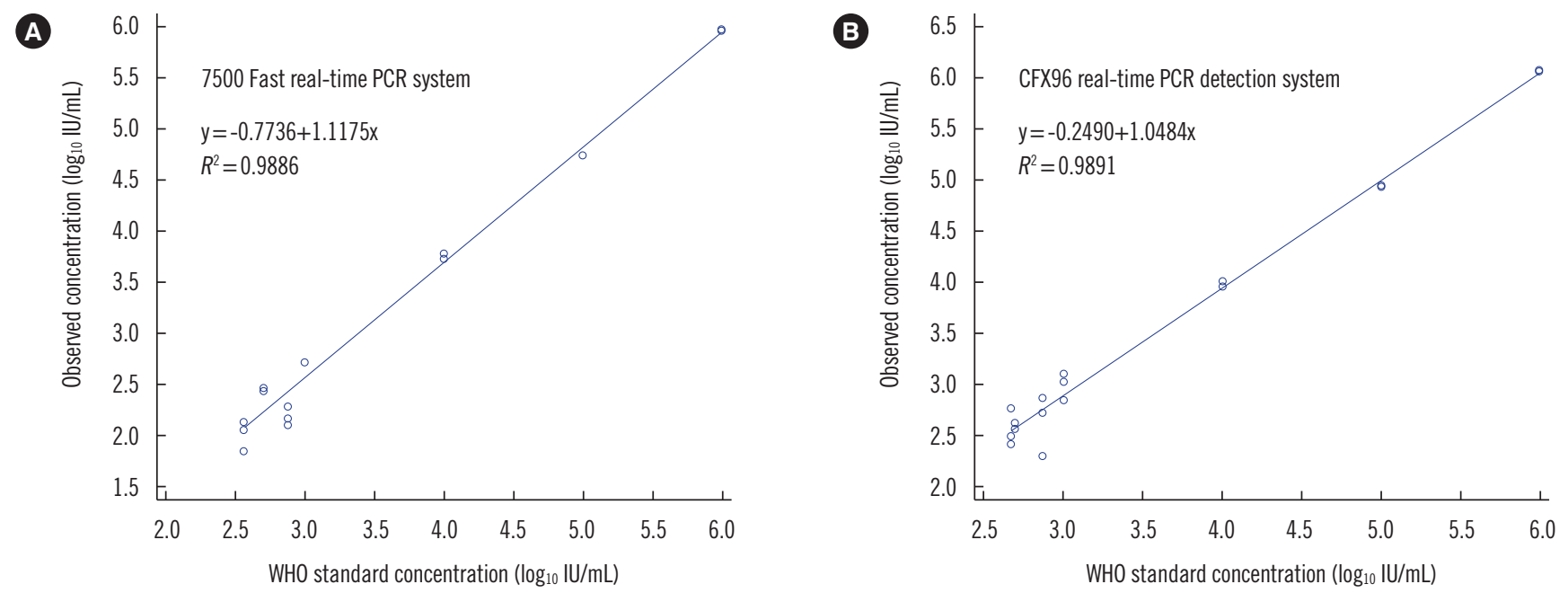

Fig. 1. Linearity of the Real-Q cytomegalovirus (CMV) Quantification kit on different real-time PCR platforms: (A) the 7500 Fast real-time PCR system and (B) the CFX96 real-time PCR detection system.
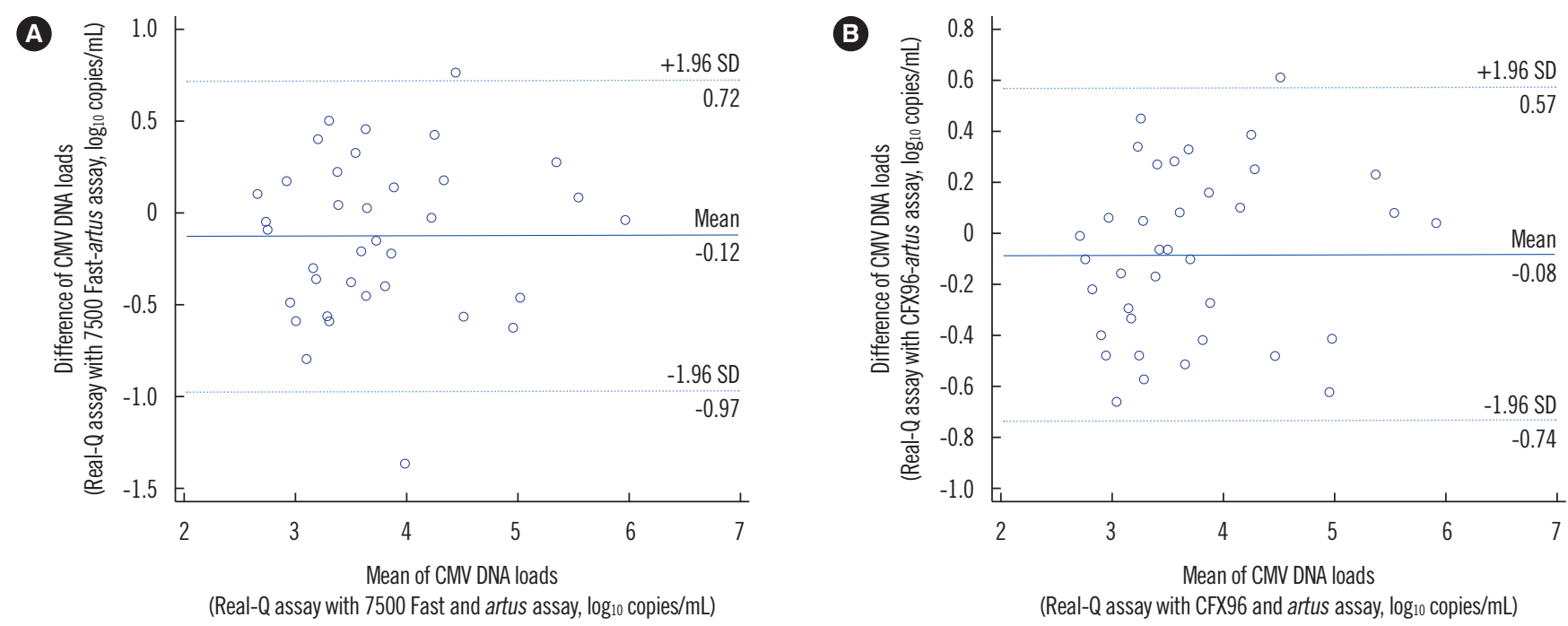

Fig. 2. Bland-Altman plot comparing the artus cytomegalovirus (CMV) RG PCR kit and the Real-Q CMV Quantification kit on different realtime PCR platforms: (A) the 7500 Fast Real-time PCR system, (B) the CFX96 real-time PCR detection system. Solid lines are the mean differences between the values; dashed lines are the mean difference plus or minus $1.96 \mathrm{SD}$ (95\% confidential interval of mean difference).

ples had a variation of $<1.0 \log _{10}$ copies $/ \mathrm{mL}$.

Several variables in CMV viral load testing complicate direct comparisons, including sample type, nucleic acid extraction method, reagents used, and instruments used for amplification and detection [9]. The WHO IS for CMV helps to standardize results and overcome variability, and conversion factors were applied to provide all the results of this study in IU/mL. We demonstrated that the conversion factors for the Real-Q assay were close to 1.0 for each real-time PCR platform.

The sample type is one of the most important pre-analytical variables; WB or plasma is typically used for CMV DNA quantifi- cation. Because both cell-free and intracellular viruses are detected in WB, CMV viral load values in WB are often higher than those in plasma [10]. The use of WB does not require a centrifugation step, and therefore provides a more convenient workflow than the use of plasma $[11,12]$. We used CMV-negative WB as a matrix in all of the performance evaluations in this study.

With regard to the analytical variables, the effects of the nucleic acid extraction method and real-time PCR instrumentation on CMV viral load results were evaluated and reported previously [13]. In this study, we extracted CMV DNA using the MagNA Pure 96 system, which was launched in 2009 for auto- 
mated nucleic acid extraction. Evaluation of the MagNA Pure 96 system using plasma and WB samples for CMV DNA quantification was recently reported $[14,15]$. Although we could not compare our results with those obtained from other DNA extraction methods, we found that the Real-Q assay coupled with the MagNA Pure 96 system is a useful clinical tool for quantifying CMV in WB. Use of an automated, high-throughput DNA extraction method would be helpful for the rapid diagnosis of CMV infection in clinical settings.

In conclusion, we found the Real-Q assay to be reliable for quantifying CMV in WB. The Real-Q assay can be used with both the 7500 Fast and CFX96 real-time PCR platforms.

\section{Authors' Disclosures of Potential Conflicts of Interest}

No potential conflicts of interest relevant to this article were reported.

\section{Acknowledgments}

This research was supported by a grant of the Korea Health Technology R\&D Project through the Korea Health Industry Development Institute (KHIDI), funded by the Ministry of Health \& Welfare, Republic of Korea (grant number: HI14C3205).

\section{REFERENCES}

1. Le Page AK, Jager MM, Iwasenko JM, Scott GM, Alain S, Rawlinson WD. Clinical aspects of cytomegalovirus antiviral resistance in solid organ transplant recipients. Clin Infect Dis 2013;56:1018-29.

2. Razonable RR. Management strategies for cytomegalovirus infection and disease in solid organ transplant recipients. Infect Dis Clin North Am 2013;27:317-42.

3. Baldanti F, Lilleri D, Gerna G. Monitoring human cytomegalovirus infection in transplant recipients. J Clin Virol 2008;41:237-41.
4. Gerna G, Lilleri D, Chiesa A, Zelini P, Furione M, Comolli G, et al. Virologic and immunologic monitoring of cytomegalovirus to guide preemptive therapy in solid-organ transplantation. Am J Transplant 2011;11: 2463-71.

5. Kraft CS, Armstrong WS, Caliendo AM. Interpreting quantitative cytomegalovirus DNA testing: understanding the laboratory perspective. Clin Infect Dis 2012;54:1793-7.

6. Pang XL, Fox JD, Fenton JM, Miller GG, Caliendo AM, Preiksaitis JK. Interlaboratory comparison of cytomegalovirus viral load assays. Am J Transplant 2009;9:258-68.

7. Fryer JF, Heath $A B$, et al. eds. Collaborative study to evaluate the proposed 1st WHO international standard for human cytomegalovirus (HCMV) for nucleic acid amplification (NAT)-based assays. Geneva, Switzerland: World Health Organization, 2010.

8. CLSI. Evaluation of detection capability for clinical laboratory measurement procedures; approved guideline-Second ed. CLSI document EP17A2. Wayne, PA: Clinical and Laboratory Standards Institute, 2012.

9. Miller S, Seet H, Khan Y, Wright C, Nadarajah R. Comparison of QIAGEN automated nucleic acid extraction methods for CMV quantitative PCR testing. Am J Clin Pathol 2010;133:558-63.

10. Lisboa LF, Asberg A, Kumar D, Pang X, Hartmann A, Preiksaitis JK, et al. The clinical utility of whole blood versus plasma cytomegalovirus viral load assays for monitoring therapeutic response. Transplantation 2011; 91:231-6.

11. Schnepf N, Scieux C, Resche-Riggon M, Feghoul L, Xhaard A, Gallien S, et al. Fully automated quantification of cytomegalovirus (CMV) in whole blood with the new sensitive Abbott RealTime CMV assay in the era of the CMV international standard. J Clin Microbiol 2013;51:2096-102.

12. Deback C, Géli J, Aitt-Arkoub Z, Angleraud F, Gautheret-Dejean A, Agut $\mathrm{H}$, et al. Use of the Roche LightCycler 480 system in a routine laboratory setting for molecular diagnosis of opportunistic viral infections: evaluation on whole blood specimens and proficiency panels. J Virol Methods 2009;159:291-4.

13. Bravo D, Clari MÁ, Costa E, Muñoz-Cobo B, Solano C, José Remigia M, et al. Comparative evaluation of three automated systems for DNA extraction in conjunction with three commercially available real-time PCR assays for quantification of plasma Cytomegalovirus DNAemia in allogeneic stem cell transplant recipients. J Clin Microbiol 2011;49:2899-904.

14. Edelmann A, Eichenlaub U, Lepek S, Krüger DH, Hofmann J. Performance of the MagNA Pure 96 system for cytomegalovirus nucleic acid amplification testing in clinical samples. J Clin Microbiol 2013;51:1600-1.

15. Mengelle C, Mansuy JM, Sauné K, Barthe C, Boineau J, Izopet J. A new highly automated extraction system for quantitative real-time PCRs from whole blood samples: routine monitoring of opportunistic infections in immunosuppressed patients. J Clin Virol 2012;53:314-9. 